Org Lett. 2007 August 2; 9(16): 3093-3096.

\title{
Stereoselective [2,3]-Sigmatropic Rearrangements of Unstabilized Nitrogen Ylides
}

\author{
Robert E. Gawley and Kwangyul Moon \\ Department of Chemistry and Biochemistry, University of Arkansas, Fayetteville, AR 72701, \\ bgawley@uark.edu
}

\section{Abstract}
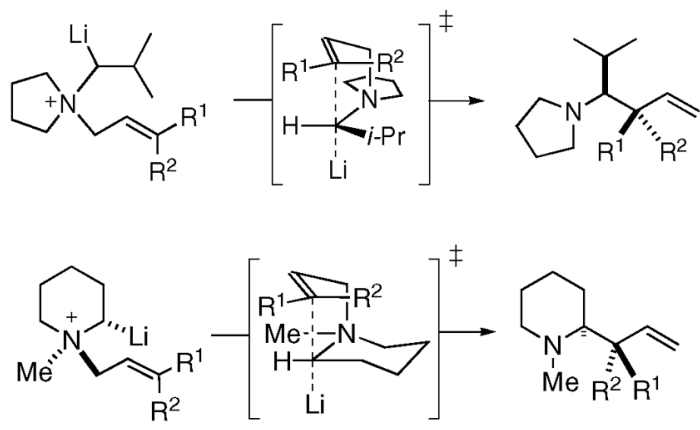

The steric course of the [2,3]-rearrangement of several unstabilized nitrogen ylides has been investigated. The reactions proceed cleanly through an anti transition state, affording modest to good yields of a single diastereomer of the product. In two examples containing an $N$-cinnamyl group, a competing [1,2]-rearrangement affords a minor product.

Electrophilic substitution reactions of $\alpha$-alkoxy-and $\alpha$-aminoorganolithium compounds (Eq 1) have been extensively studied, and constitute an important class of synthetic methods, with hundreds of applications reported so far. ${ }^{1,2}$ A second class of carbon-carbon bond forming reactions utilizing these reactive intermediates is sigmatropic rearrangements. ${ }^{3,4}$ In 1978 , Still and Mitra reported the first example of a [2,3]-rearrangement of an organolithium generated by tin-lithium exchange, ${ }^{5}$ which was later shown to be invertive at the lithium-bearing carbon (Eq 2). ${ }^{6-8}$

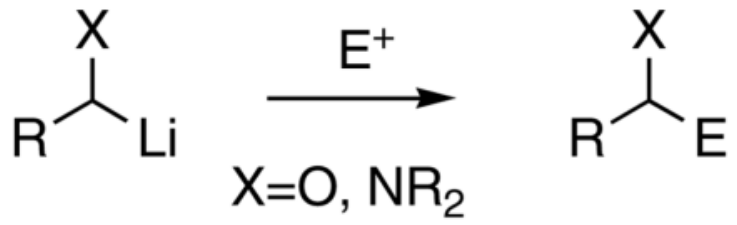




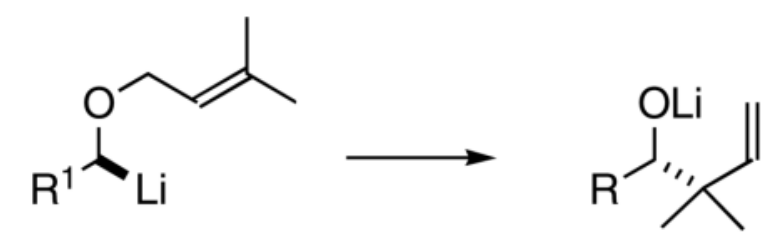

The nitrogen (aza) analog of the Still-Wittig [2,3]-rearrangement (Eq 3) is less facile, due primarily to the lower stability of the lithium amide compared to the lithium alkoxide product of the oxygen version. $3,4,9,10$ Once generated, the $N$-allyl $\alpha$-aminoorganolithium often follows competing [1,2]- and [2,3]-rearrangement pathways (Eq 3). ${ }^{11-13}$ Quaternization of the nitrogen (Eq 4) with a trimethylsilyl group, ${ }^{14}$ boron trifluoride, ${ }^{15}$ or an alkyl group 13 , 16 accelerates the concerted [2,3]-rearrangement over the radical-mediated [1,2]rearrangement of the ylides. The steric course of the anionic and ylide aza-[2,3]-rearrangements is invertive if the metal bearing carbon is stereogenic (Eqs 3 and 5), ${ }^{13}$ but the stereoselectivity at the migration terminus of nitrogen ylides has only been explored in stabilized ylides such as the enolate shown in Eq 4. In most cases, the diastereoselectivity is modest, ${ }^{16-18}$ with only a few examples of high selectivity in auxiliary mediated processes. ${ }^{19,20}$ We now report the results of our studies on the diastereoselectivity at the migration terminus of the [2,3]rearrangement of several unstabilized, lithionitrogen ylides (Eq 5), in which we find that the rearrangement is highly stereoselective. Note: Strictly speaking, the ylide is the zwitterion having a positive nitrogen and a negative carbon. Since the anionic carbon is stereogenic, we draw the carbon-lithium ion pair as a bond.

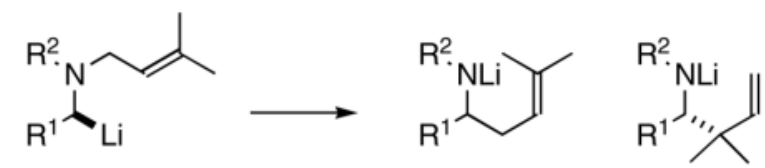<smiles>[R]C(O)=C[NH+]([R][H])CC=C([Z])F</smiles>
$[2,3]$-product<smiles>[Z]C(F)=CCN([R7])[3H]</smiles>

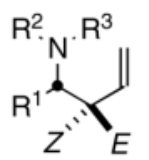

$[2,3]-$ product

Stannane $\mathbf{1}$ is a challenging test of the methodology for two reasons. Firstly, stannane $\mathbf{1}$ fails to undergo tin-lithium exchange, so it was of interest to determine whether quaternization of the nitrogen would facilitate the exchange. Secondly, we wanted to evaluate the diastereoselectivity of the [2,3]-rearrangement in the context of acyclic stereoselection. To test the first point, $\mathbf{1}$ was simply quaternized with methyl iodide. Treatment of the methiodide salt 
with butyllithium in THF at $-78{ }^{\circ} \mathrm{C}$ for $1 \mathrm{~h}$, quenching with methanol, and silica gel chromatography afforded a $69 \%$ yield of tetrabutyltin, indicating that transmetalation to the ylide is facile in this system. Quaternization of racemic 1 with $E$-crotyl bromide, and $E$ - and $Z$-cinnamyl bromide affords ammonium salts $\mathbf{2 a - c}$, as shown in Scheme 1. For some compounds, anion exchange from halide to hexafluorophosphate facilitated handling, provided a salt that was less hygroscopic, and increased solubility in organic solvents (see Supporting Information).

As illustrated in Scheme 2, stannylammonium ions 2a-c were treated with butyllithium in THF at $-60{ }^{\circ} \mathrm{C}$ to effect transmetalation and stirred at that temperature for $20-24 \mathrm{~h}$. After workup and column chromatography, amines $\mathbf{5 a}-\mathbf{c}$ were obtained in the yields shown in Table 1, entries $1-3$.

Of interest in these rearrangements is the possibility of two transition state conformers, syn and anti $\mathbf{4 a}-\mathbf{c}$, which would afford diasteromeric products $\mathbf{5}$ or $\mathbf{6}$, and possibly [1,2]rearrangement product 7 . In all cases, only one diastereomer was isolated. Independent synthesis of $\mathbf{5 b}$ and $\mathbf{5 c}$ established the relative configurations (see Supporting Information). It appears that the [2,3]-rearrangement prefers the anti transition state 4, independent of alkene geometry, even though anti $\mathbf{4} \mathbf{c}$ having a $Z$ double bond appears somewhat more congested. The lower yield from the $Z$-cinnamyl intermediate $\mathbf{3 c}$ may indicate that steric crowding in the anti transition state slows the rearrangement, allowing pathways toward nonproductive decomposition to become more competitive; in this case, there were numerous unidentified polar byproducts. It is noteworthy that under these conditions, none of the $[1,2]$-products $7 \mathbf{a}$ c were detected.

If $\mathrm{R}^{2}$ and $\mathrm{R}^{3}$ in Eq 5 are different, then the nitrogen is a stereocenter and the stereoselectivity of the rearrangement will rely on the stereoselective quaternization of the nitrogen. To probe the diastereoselectivity of the rearrangement in cyclic systems, we chose racemic $N$-methyl-2(tributylstannyl)-piperidine, 8 . Based on precedent from a single example in an earlier report, 13 we anticipated that alkylation of $\mathbf{8}$ would occur trans to the tin.

In the event, alkylation of $\mathbf{8}$ with $E$-crotyl bromide and with $E$ - and $Z$-cinnamyl bromide afforded ammonium ions $\mathbf{9 a - c}$, with $90-94 \%$ diastereoselectivity, as indicated by integration of the $\mathrm{N}$-methyl peaks in the NMR (Scheme 3). Again, exchange of the halide anion for $\mathrm{PF}_{6}{ }^{-}$often facilitated handling of the salt, increased its solubility in organic solvents, and made it less hygroscopic.

Transmetalation of $\mathbf{9 a - c}$ afforded ylides $10 \mathbf{a}-\mathbf{c}$, and ultimately their rearrangement products, as summarized in Table 1, entries 4-6, and illustrated in Scheme 4. The E-crotyl ylide 10a rearranged to a mixture of isomers, of which piperidine 12a was the major $(92 \%)$ component. The isomers were not obtained in sufficient quantity to identify; one may be the [1,2]-product 14a, while others are diastereomers that could have arisen from transition structure syn-11, or from minor contaminants of cis alkene ylide $\left(\mathbf{1 0}, \mathrm{R}^{2}=\mathrm{Me}, \mathrm{R}^{1}=\mathrm{H}\right)$. Trans-cinnamyl ylide $\mathbf{1 0 b}$

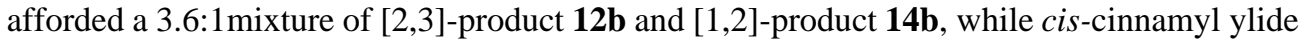
10c afforded a 6.9:1 mixture of [2,3]-product 12c and [1,2]-product 14c. None of the diastereomeric products $\mathbf{1 3 b}-\mathbf{c}$ were detected by GC-MS, and the structure of $\mathbf{1 2 b}$ was confirmed by independent synthesis (See Supporting Information). To further confirm these assignments, stannane 8 was transmetalated with $\mathrm{BuLi}$ at $-78{ }^{\circ} \mathrm{C}$ in THF, and alkylated with trans cinnamyl bromide according to our established procedure. ${ }^{21}$ Analysis of the product mixture revealed a mixture of $S_{N} 2$ product $14 b$, along with $S_{N} 2^{\prime}$ products $12 b$ and $13 b$. In the [2,3]-rearrangement of $\mathbf{1 0 b}-\mathbf{c}$, the extra stabilization afforded by the phenyl group probably facilitates homolytic cleavage of the allylic $\mathrm{C}-\mathrm{N}$ bond to produce $\mathbf{1 4 b}-\mathbf{c}$ after radical recombination. In summary, nitrogen ylides $\mathbf{3 a}-\mathbf{c}$ and $\mathbf{1 0 a}-\mathbf{c}$ rearrange preferentially through 
transition structures anti-4 and anti-11, creating two adjacent stereocenters with a high degree of stereoselectivity. Further applications of the [2,3]-rearrangement of unstabilized nitrogen ylides are under active investigation and will be reported in due course.

\section{Supplementary Material}

Refer to Web version on PubMed Central for supplementary material.

\section{Acknowledgements}

Acknowledgement is made to the donors of the Petroleum Research Fund, administered by the American Chemical Society, for partial support of this work. We also thank NIH for partial support (GM 56271). Core facilities were funded by NIH (P20 R15569) and the Arkansas Biosciences Institute. We are grateful to Dr Donna Iula for exploratory experiments.

\section{References}

1. Hoppe D, Marr F, Brüggemann M. Top Organomet Chem 2003;5:61-138.

2. Beak P, Johnson TA, Kim DD, Lim SH. Top Organomet Chem 2003;5:139-176.

3. Markó, I. Comprehensive Organic Synthesis. In: Trost, BM.; Fleming, I., editors. Selectivity, Strategy and Efficiency in Modern Organic Chemistry. 3. Pergamon; Oxford: 1991. p. 913-974.

4. Tomooka, K. The chemistry of organolithium compounds. Rappoport, Z.; Marek, I., editors. John Wiley \& Sons, Ltd.; Chichester: 2004. p. 749-828.

5. Still WC, Mitra A. J Am Chem Soc 1978;100:1927-1928.

6. Verner EJ, Cohen T. J Am Chem Soc 1992;114:375-377.

7. Hoffmann R, Brückner R. Angew Chem Int Ed Engl 1992;31:647-649.

8. Tomooka K, Igarashi T, Watanabe M, Nakai T. Tetrahedron Lett 1992;33:5795-5798.

9. Nakai T, Tomooka K. Pure Appl Chem 1997;69:595-600.

10. Gawley, RE.; Coldham, I. The Chemistry of Organolithium Compounds (Patai Series). Rappoport, Z.; Marek, I., editors. Wiley; Chichester: 2004. p. 997-1053.

11. Heard GL, Yates BF. J Org Chem 1996;61:7276-7284. [PubMed: 11667650]

12. Coldham I. J Chem Soc Perkin Trans 1993;1:1275-1276.

13. Gawley RE, Zhang Q, Campagna S. J Am Chem Soc 1995;117:11817-11818.

14. Murata Y, Nakai T. Chemistry Letters 1990:2069-2072.

15. Kessar SV, Singh P, Singh KN, Kaul VK, Kumar G. Tetrahedron Lett 1995;36:8481-8484.

16. Coldham I, Middleton ML, Taylor PL. J Chem Soc, Perkin Trans 1 1998:2817-2821.

17. Roberts E, Sançon JP, Sweeney JB, Workman JA. Org Lett 2003;5:4775-4777. [PubMed: 14653671]

18. Zhou CY, Yu WY, Chan PWH, Che CM. J Org Chem 2004;69:7072-7082. [PubMed: 15471455]

19. Aggarwal VK, Fang Gy, Charmant JPH, Meek G. Org Lett 2003;5:1757-1760. [PubMed: 12735770]

20. Workman JA, Garrido NP, Sançon J, Roberts E, Wessel HP, Sweeney JB. J Am Chem Soc 2005;127:1066-1067. [PubMed: 15669822]

21. Gawley RE, Zhang Q. J Org Chem 1995;60:5763-5769. 
<smiles>CC(C)C([SbH2])N1CCCC1</smiles>

1

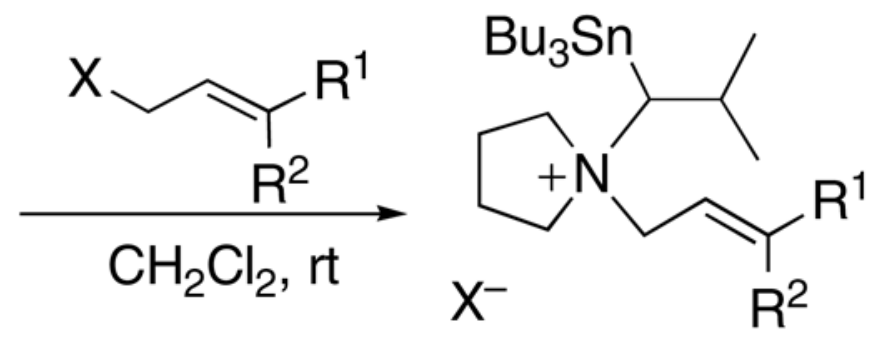

2a: $R^{1}=M e, R^{2}=H(95 \%)$

2b: $R^{1}=P h, R^{2}=H(95 \%)$

2c: $R^{1}=H, R^{2}=P h(87 \%)$

Scheme 1. 

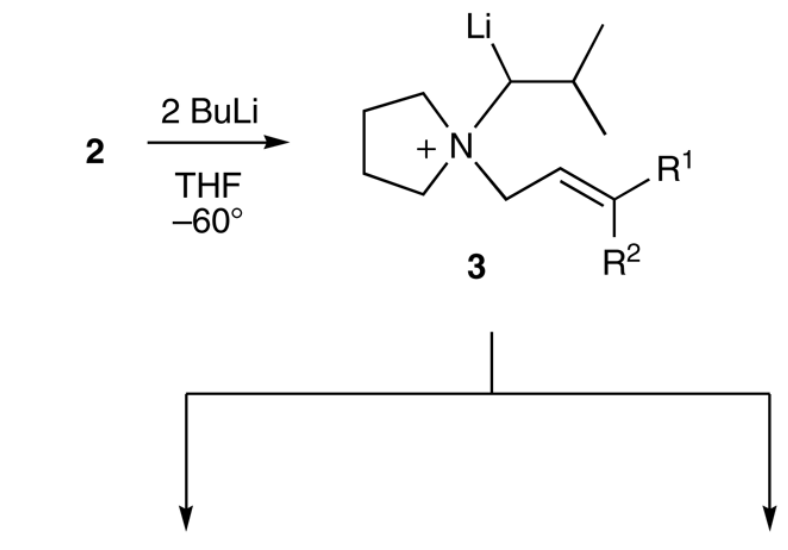

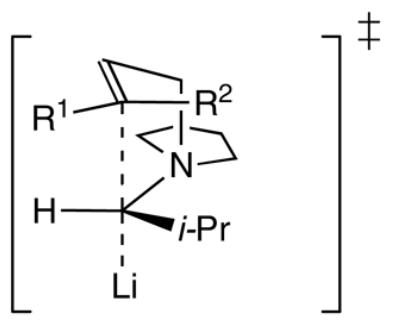

anti-4

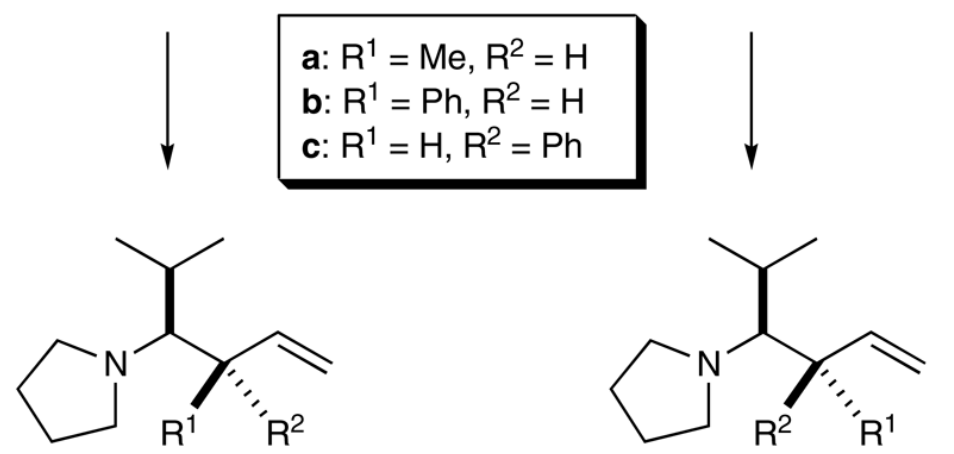

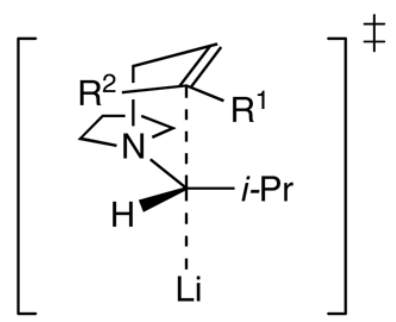

syn-4

5

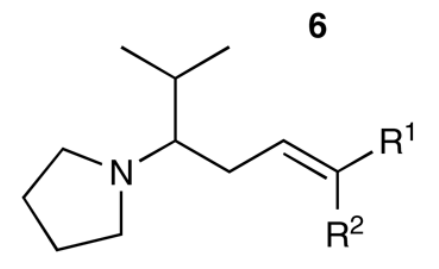

Scheme 2. 
<smiles>[X]CC=C([R7])[R]Cl</smiles><smiles>[R15][As]C1CCCC[N+]1(C)CC=C([R7])[R7]</smiles>

8

9a: $R^{1}=M e, R^{2}=H$

(90\%, 93:7 dr)

9b: $\mathrm{R}^{1}=\mathrm{Ph}, \mathrm{R}^{2}=\mathrm{H}$

(90\%, 94:6 dr)

9c: $R^{1}=H, R^{2}=P h$

(85\%, 90:10 dr)

Scheme 3. 

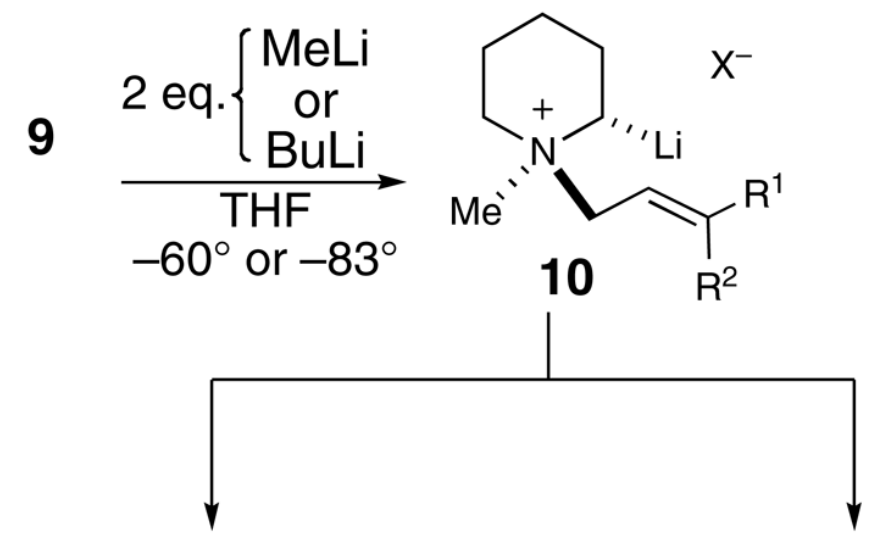

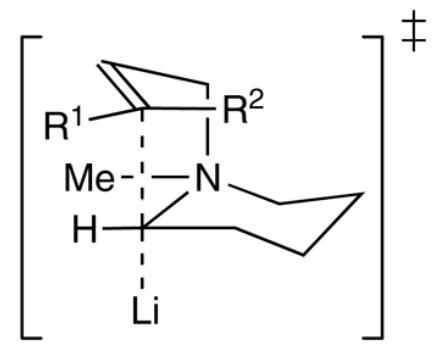

anti-11

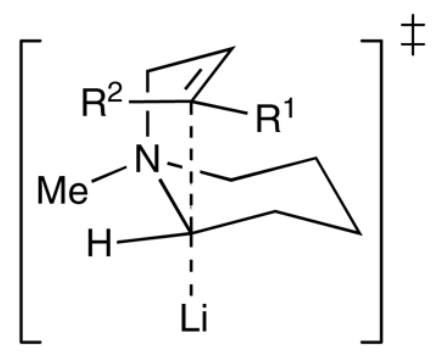

syn-11

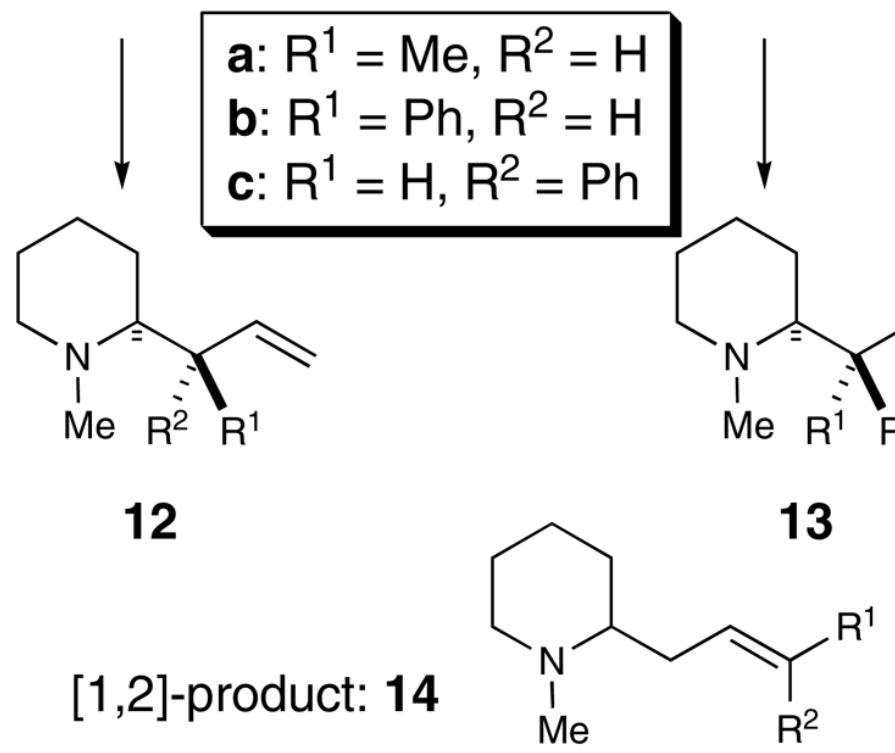

Scheme 4. 


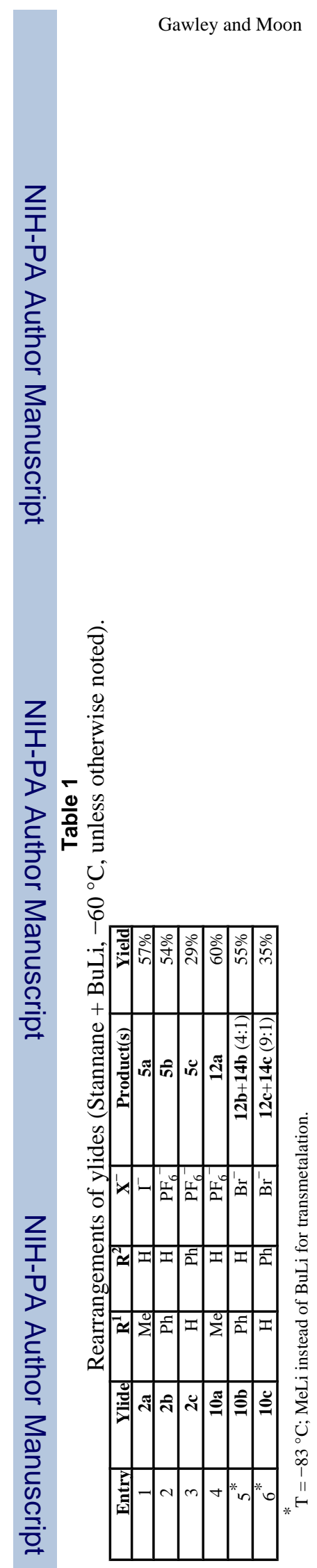

Page 9

Org Lett. Author manuscript; available in PMC 2008 August 21. 